\title{
The measurement-aided welding cell—giving sight to the blind
}

\author{
Valtteri Tuominen $^{1}$ (iD \\ Received: 5 September 2015 / Accepted: 30 November 2015 / Published online: 11 December 2015 \\ (C) The Author(s) 2015. This article is published with open access at Springerlink.com
}

\begin{abstract}
This article introduces the concept of a measurement-aided welding cell (MAWC). It then focuses on developing the MAWC for body and chassis components in the automotive industry. Industry 4.0 requires flexibility and reconfigurability from manufacturing systems, which has been addressed by cellular manufacturing systems (CMS). Traditional automotive welding technology is not flexible enough to be used as a CMS. So, the core of automotive production does not meet the needs of next-generation manufacturing and Industry 4.0. For the first time, this demand has been answered-by the MAWC. The MAWC is based on two handling robots, a welding robot and an optical measurement system, all integrated into one welding cell. The measurement system controls guides and gives feedback to the handling and welding robots. This way, accurate welding is based on actual part-to-part adjustment, rather than hard mechanical tooling. The lack of hard mechanical tooling allows flexibility. Measurement-assisted assembly and machining is not new. However, it has not previously been applied to complex welding processes, because traditional measurement technologies have not been satisfactory. A newly developed system using multi-camera measurement technology meets the flexibility requirements. The technology required for a MAWC is reviewed and found to be in common use in the automotive industry. Three development projects are presented in which the main functions of a MAWC are successfully demonstrated. Two of these projects were done with BMW. A MAWC allows the manufacturing process to immediately
\end{abstract}

Valtteri Tuominen

valtteri.tuominen@gmail.com

1 Aalto University, Espoo, Finland swap to a different product on the same line, increasing the production line utilisation rate and making it possible to produce several low-volume products in one manufacturing system. So, the MAWC will not only yield benefits from its scalable capacity and global decentralization, but it will also open new business opportunities for manufacturing lowvolume luxury car parts or post-production spare parts.

Keywords Measurement-aided welding cell $\cdot$ Flexible manufacturing $\cdot$ Reconfigurable manufacturing $\cdot$ Intelligent feedback loop · Optical measurement · Flexible measurement . Robot welding $\cdot$ Automotive industry

\section{Introduction}

The global manufacturing industry, especially leading innovative fields such as automotive, needs to regularly introduce new product lines and enhancements to existing products to maintain competitiveness. This shortens the product life cycle, and manufacturing technology, processes and operations must respond.

Product variety in the automotive industry has more than doubled in the last decade, while product life cycle has decreased from 8 to 4 . For example, the first Volkswagen Golf motor vehicles rolled off the production line in 1974, and the model is in 2015 in its seventh generation. Since its launch, the product life cycle has shortened from 10 to 3 years. Also, the development time for a new Golf has been shortened from 48 to 25 months and is expected to drop to 20 months by 2018 [1].

At the same time, there are significant market pressures on new products to be more affordable, both in their initial production costs and in their overall life cycle costs. This forces 
manufacturers to continually strengthen their production finances to sustain competitiveness [2]. The result of market and industry trends is a movement towards "mass customization," where the manufacturing base is both highly flexible and efficient.

Can you imagine a workshop full of blind blacksmiths? And can you imagine suddenly giving them sight? This article is about giving sight to the blind.

\subsection{Fourth industrial revolution}

The "fourth industrial revolution" refers to the next generation of manufacturing, where automation technology is improved by self-optimization and intelligent feedback. This is needed to support the workers in an increasingly complex manufacturing environment. The fourth industrial revolution is discussed under different terms and concepts.

Industry 4.0 is a term that was first introduced in 2011, when a set of recommendations were presented to the German government by the Working Group on Industry 4.0. It is a long-term vision in which the deindustrialization of the European manufacturing sector is being reversed. In practical terms, it refers to smart factories where production and quality inspection activities are automated and flexible.

Similar long-term goals are being pursued by the Smart Manufacturing Leadership Coalition and the Industrial Internet initiative in the USA. Despite its different names, the fourth industrial revolution is all about intelligent feedback within the manufacturing process.

The first steps towards mass customization and nextgeneration manufacturing were enabled by a significant reduction in product development time brought about by the use of CAD tools about 2 decades ago.

Also, on the side of process capability, there has been heavy progress towards mass customization. Some of the most influential examples are assembly automation [3], the Volvo system, Total Quality Control, the Toyota system, the lean system [4-8] and integrative product development [9, $10]$.

\subsection{Literature review}

Development in manufacturing systems has not kept up with CAD and process capability development [11].

Plenty of the literature addresses the challenge of mass customization in manufacturing systems. This topic has been discussed using many different terms, such as "transformability" [12, 13], "agility" [14-17] and "flexibility" [18-20].

The concept of a flexible manufacturing system (FMS) was introduced in the 1980s. Basically, an FMS consists of a numerically controlled (NC) machine and a computer control system [21]. The FMS was good with customization, but not mass customization [11].

Reconfigurable manufacturing emerged to address the needs of mass customization [22, 23]. In addition to enabling the manufacture of flexibly different products, a reconfigurable manufacturing system (RMS) covers the problem of changing production location due to globalization, while still maintaining quality. Future software would read in the changed customer CAD files and automatically generate $\mathrm{CNC}$ programs in the RMS.

An RMS can be considered as something in between the flexible FMS and the traditional, non-reconfigurable dedicated manufacturing system (DMS) [11, 24], as seen in Fig. 1. This kind of reconfigurability is needed for the next generation of manufacturing and mass customization $[11,25,26]$.

A cellular manufacturing system (CMS) is a strategy that enhances the productivity in a factory by improving flexibility and efficiency. It addresses the increasing demand for midvolume and mid-variety product mixes derived from shortening product life cycles, which the traditional job shops and flow lines (DMLs) cannot address. So, the CMS covers some of the same issues as the RMS, but the CMS has been shown to work in practice with favourable results, unlike the RMS [27-31].

In a CMS, machines are organized near each other as machine cells to process a collection of similar parts (part families) on dedicated clusters of machines or manufacturing processes. To be able to adapt to changing demand, the CMS requires reconfigurable manufacturing machines. These machines are designed so that their hardware and software components can quickly adjust their functionality within the part family in response to sudden changes in market demand.

The design of manufacturing cells has been an attractive research topic since 1990. In the literature, many solutions have been proposed to improve the adaptation of cellular systems to market dynamics.

Many authors recommend developing algorithms to minimize bottleneck costs and optimize the average cell utilisation. More current papers focus on algorithms for multi-objective optimization that integrates production planning, back order,

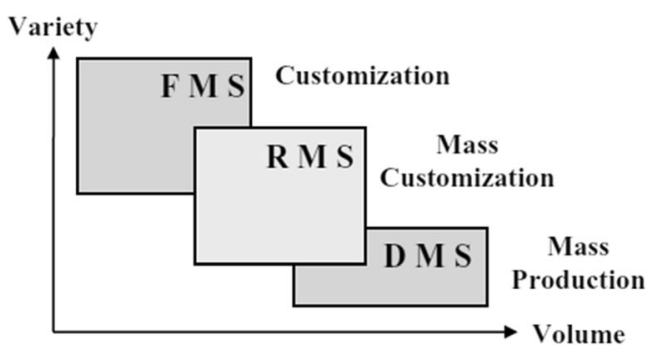

Fig. 1 Comparison of the flexible manufacturing system (FMS), the reconfigurable manufacturing system (RMS) and the dedicated manufacturing system (DMS). Image: [11] 
subcontracting, dynamic system reconfiguration and several other attributes [32].

Several methodologies have been proposed to take into account market uncertainty by optimizing different cost components: intra- and inter-cell material handling costs, machine purchase costs, reconfiguration costs and movement costs. [33]

A more integrated approach for CMS design has been introduced where production planning and system reconfiguration decisions are incorporated, including alternate process routings, operation sequences, duplicate machines, machine capacity and lot splitting [34].

The most recent literature studies the effect of dynamic reconfiguration using reconfigurable machines on different types of manufacturing systems, including the use of a remainder cell [33].

\subsection{What's new here?}

There are a few points that stand out from this literature review.

Firstly, cellular manufacturing with reconfigurable machines is clearly the direction in which manufacturing is heading. Manufacturing systems need to adapt quickly to market changes.

Secondly, most of the existing literature focuses on the development of algorithms for optimizing generic manufacturing processes. These studies do not consider the actual manufacturing technology, its limitations and its practical applications. In the few studies where the technology is examined, the scope of the study is limited to machining and tooling, such as CNC machines. Some simple assembly applications have been studied, but no research has been done on complex welding processes.

Thirdly, very little, if anything, has been said about how the eventual output of the manufacturing process is controlled.

All of these must be taken into account in the automotive body and chassis manufacturing processes which are based on welding. With a couple of exceptions in carbon fibre and riveting, all body and chassis components are assembled with either spot welding or arc welding.

Today, automated welding processes are based on inflexible mechanical welding fixtures, making them fall straight into the category of dedicated manufacturing lines (DML). The welding fixtures of today do not allow practically any of the reconfigurability required by cellular manufacturing systems.

This brings the frequent question: How can you develop the welding process to fit the next manufacturing generation, Industry 4.0? Based on the extant literature, this article gives an answer to this question. Here, cellular manufacturing and automotive welding process will be combined for a solution.

Measurement-assisted manufacturing operations are fairly common in modern industrial applications. However, the complexity of the welding process sets high demands on the measurement system: speed, flexibility, global calibration volume and the ability to inspect seams.

Until 2009, there was no measurement technology available which would meet these requirements. This article is the first to introduce a measurement-assisted manufacturing operation that requires such a complicated measurement task.

The automotive industry is one of the largest, if not the largest industry in the world, measured by almost any indicator. Body and chassis manufacturing form the very core of the industry. That core is failing market demand, which elsewhere is addressed by the development of cellular manufacturing systems. This article provides a technological answer to this problem.

\subsection{Structure of this article}

The majority of the research reported in the literature focuses on generic optimization algorithms. This article focuses instead on practical technology within a specific industrial application.

Here, the concept of a measurement-aided welding cell (MAWC) is introduced. The MAWC helps satisfy the demands of flexible and reconfigurable manufacturing in the challenging welding process. Rather than heavy tooling and mechanical fixtures, the operating principle is measurementbased control of the welding process.

Section 2 presents the design and layout of the MAWC.

Section 3 explains the operating principle and describes the process flow. The basic idea of three-level measurement guidance is presented.

Section 4 goes through all the technical components needed in a MAWC. It is established that all required technologies are already easy to find in the automotive industry, including the new measurement technology.

Section 5 presents three completed development and test projects. In these projects, level 1 and level 2 measurement guidance and other MAWC functionality are demonstrated in practice. Two of the projects were done together with BMW in Dingolfing, Germany.

Section 6 explains the benefits of MAWC-based manufacturing by comparing it to a traditional DWL, using the production of instrument panel supports as a case example.

Section 7 summarizes, concludes and discusses the issues presented in this article.

\section{The design of measurement-aided welding cells (MAWC)}

During welding, two components need to be held against each other. Traditionally, this has been done by heavyweight 
mechanical fixtures. If another product needs to be welded, another set of fixtures is needed. This is not reconfigurable.

A MAWC is designed so that two flexible robots with adjustable and interchangeable grippers can hold any components against each other during the welding. If another product needs to be welded, the same robots will hold the new components and do that welding as well. The ability to use the same cell for different products makes the MAWC reconfigurable. The required technology is already commonly used in the automotive industry, as can be seen in Sect. 4.

Multiple sources of dimensional uncertainty combine to make it impossible to do this without controlling and adjusting the robot positions with real-time measurement.

Each MAWC is based on the principle that the welding operation is controlled by an integrated real-time measuring system giving guidance and intelligent feedback. The integrated measurement system uses cameras that are installed on the camera frame which surrounds the complete welding cell, as seen in Fig. 2. By photographing the complete cell volume, the measurement system can flexibly measure any objects within the volume.

The components to be welded together are held in position by two handling robots (these are the white robots in Fig. 2). A third robot is the welding robot (this is the blue robot in Fig. 2).

The components are fed in to the cell on two conveyor belts, which have adaptable fixtures to hold the components. The different geometrical characteristics of the components (tube or sheet metal, small or large, etc.) require that the robots must change their grippers. Different grippers are available from the gripper holster. In addition to being interchangeable, the grippers also need to be adjustable.

The technical elements and required technology are reviewed in more detail in Sect. 4.

\section{The MAWC welding process}

In the traditional DWL welding process, the components to be welded are placed into a heavyweight mechanical

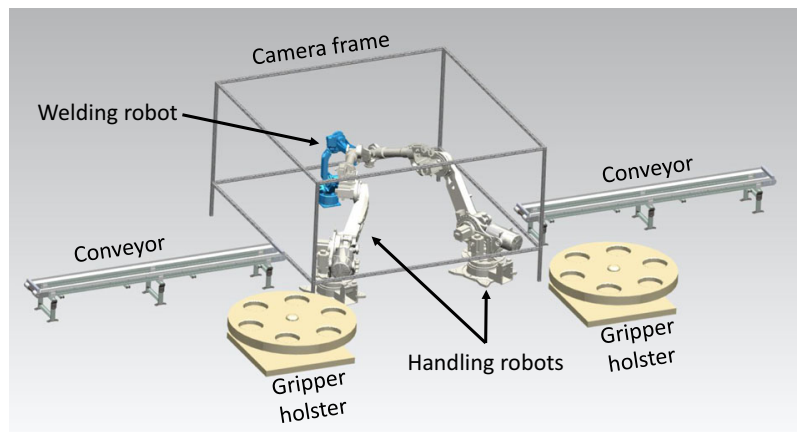

Fig. 2 Layout design and components of a measurement-aided welding cell welding fixture. After this, the welding robot welds all the components together. A typical body and chassis component might have anything from just a few to dozens of components to be welded. For example, an instrument panel support (IPS) has 15 components. All 15 components are welded together in only three stages, which are called welding operations (OPs). The left side of Fig. 3 shows the three successive steps in the welding process of an instrument panel support.

However, a MAWC welds only one additional component at a time. This results in 15 separate operations, each building on the one before it. This is illustrated on the right side of Fig. 3.

\subsection{Cycle time}

The full part-to-part manufacturing cycle time can be calculated by estimating the time of each task within one operation (OP). One OP consists of the following steps:

- Handling robots grip components (3 s).

- Handling robots position the components in their welding position (2 $\mathrm{s})$.

- Cameras measure component positions, level 1 guidance (1 s).

- Handling robots reposition components based on level 1 guidance ( $2 \mathrm{~s})$.

- Cameras measure component positions (1 s).

- Welding robot performs the welding operation $(5 \mathrm{~s})$.

- Cameras measure the resulting sub-assembly, level 2 guidance (1 s).

This results in an OP run time of $15 \mathrm{~s}$. In the case example, it took 15 OPs to weld the IPS, each run in sequence one after the other. Therefore, the complete part-to-part cycle time is $15 \mathrm{~s} \times 15 \mathrm{OPs}=3 \mathrm{~min}$ and $45 \mathrm{~s}$.

\subsection{Controlling dimensional variation}

The dimensional variation seen in the final assembled part comes from several sources, including sub-component accuracy and welding distortion. One major source of variation is the cumulative positioning inaccuracy (Pos $O P$ ) of the components in all the welding operations:

$\sqrt{\left(\mathrm{PosOP}_{1}\right)^{2}+\left(\mathrm{PosOP}_{2}\right)^{2}+\ldots+\left(\mathrm{PosOP}_{n}\right)^{2}}$

If we assume a positioning accuracy of $0.5 \mathrm{~mm}$ for each of the three welding operations, the final dimensional variation coming from cumulative positioning inaccuracy would be $0.87 \mathrm{~mm}$. The typical designed dimensional tolerance for an instrument panel support is around $1 \mathrm{~mm}$. 
Fig. 3 Welding assembly process of an IPS with DWL (left) and MAWC (right)

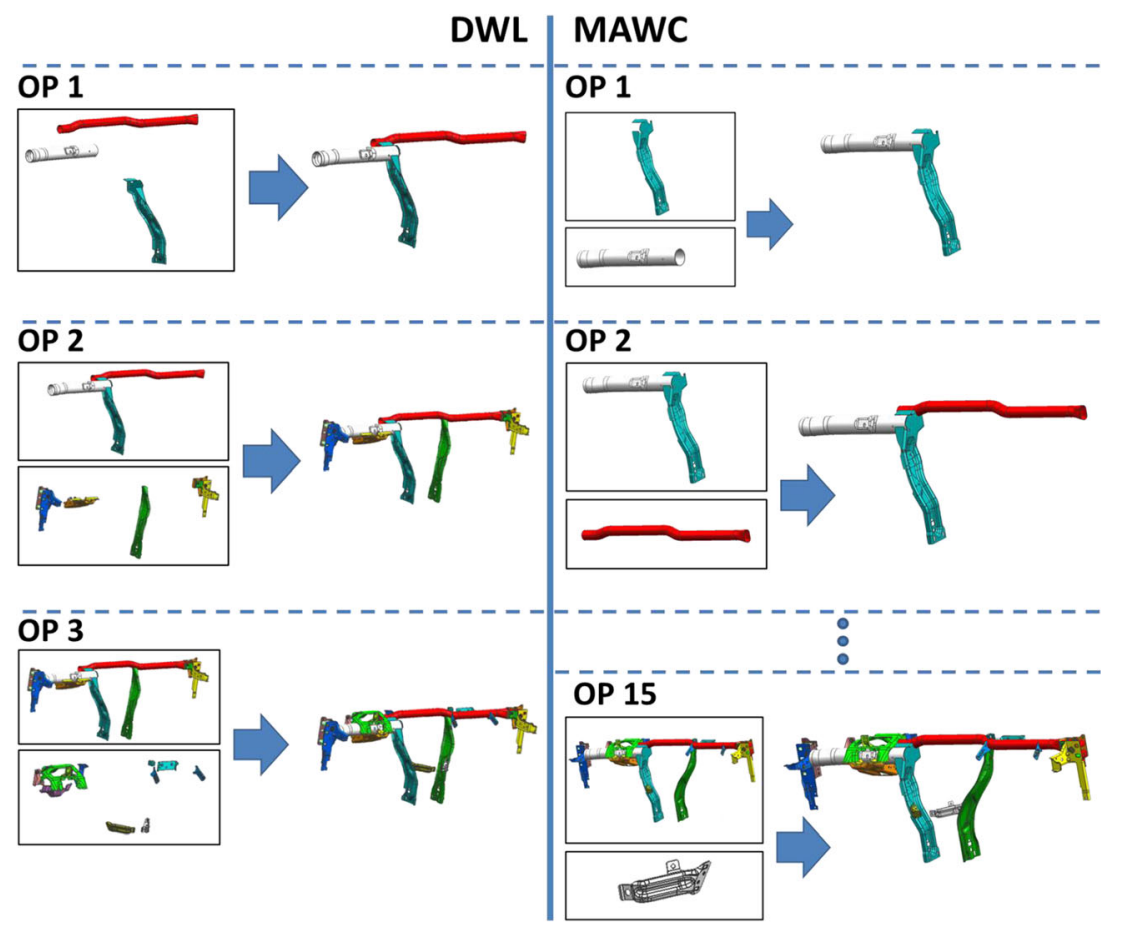

Now, in a MAWC, there are 15 welding operations. Instead of heavyweight fixtures, the positioning of components is done with robots gripping parts that arrive on conveyor belts, so positioning is significantly worse than that with the heavyweight fixtures. At best, we can assume a positioning accuracy of 1-2 mm for each components. With 15 consecutive welding operations, the resulting dimensional variation in the final assembly is between 3.87 and $7.75 \mathrm{~mm}$.

Welding robots will always accurately follow their preprogrammed welding path. But, with such a large variation, the intersection of the two components is not always in the same place as the welding path. It is impossible to automatically weld components with such large variation.

In addition to not meeting the designed dimensional tolerances, automatic welding is not even possible unless the positioning accuracy of the components is significantly improved.

In a MAWC, the necessary improvement in component positioning accuracy is done by providing real-time measurement guidance and intelligent feedback. The welding process in a MAWC includes three levels of measurement guidance:

Level 1 Pre-welding component positioning

Level 2 Post-welding inspection

Level 3 Inter-operation compensation

Figure 4 presents these three levels of guidance. For comparison, Fig. 5 shows the measurement analysis process in adjusting traditional DML welding in which the analysis is run as a separate isolated operation at the end of the process.

Figure 6 shows a flow chart that explains the decision points in the guidance process for MAWC welding in more detail.

\subsection{Level 1 guidance: pre-welding component positioning}

The welding process starts in a MAWC when the handling robots (HR) take components from conveyor belts that have simple programmable pins to hold each component roughly in its correct position and orientation.

The handling robots now move to the pre-programmed welding position. Even though the positioning repeatability of the handling robot is $0.1 \mathrm{~mm}$, the eventual position of the component is affected by the positioning accuracy of the conveyor, the gripping accuracy of the robot and the internal dimensional variation of the component itself. This results in a true positioning accuracy of $1-2 \mathrm{~mm}$.

At this point, the system measures the two components that are held by the handling robots. One of the handling robots is "master" and the other is its "slave". The position of the slave component is calculated with reference to the master component. This difference is then made into a transformation matrix to adjust the position of the slave component to achieve a close-to-nominal position.

After the components have been adjusted, the system calculates the adjustments needed for the welding path. The welding robot receives this information as a transformation 


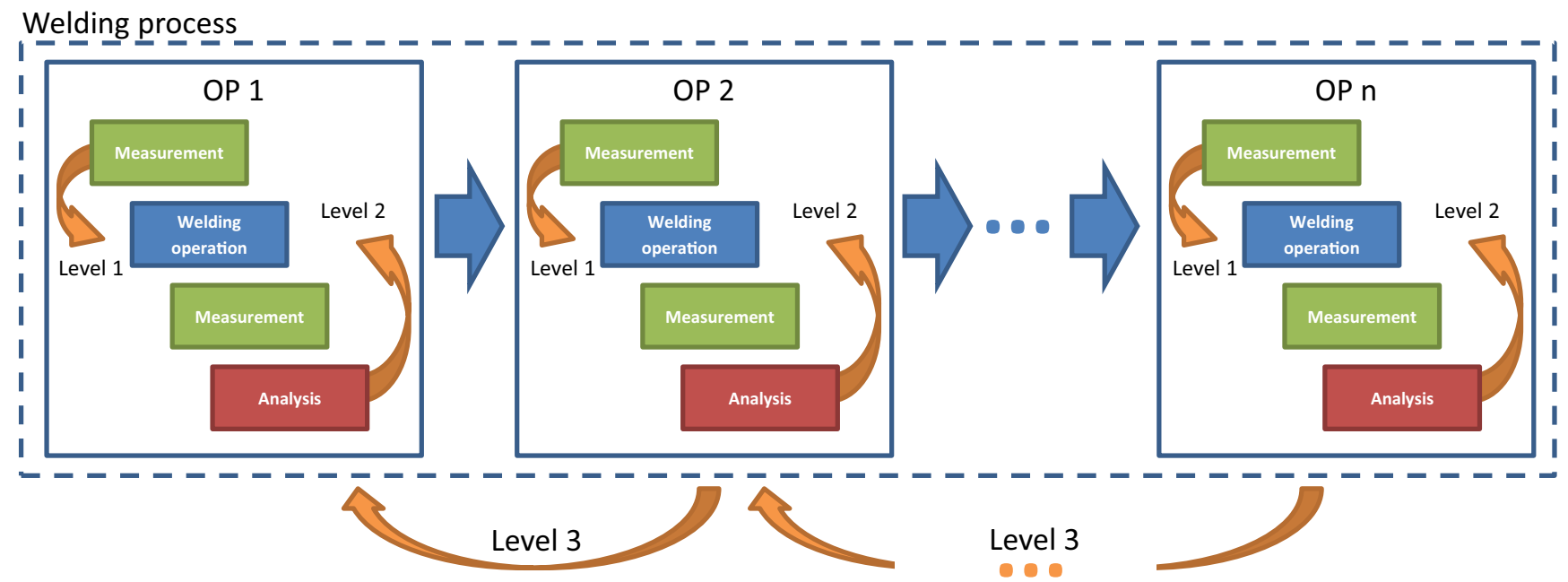

Fig. 4 The three levels of guidance in a MAWC welding process

matrix. With this adjustment to the preprogramed welding path, the welding robot welds the components together.

This functionality has been shown to work in practice in development and test projects, as outlined in Sects. 5.1 and 5.2.

\subsection{Level 2 guidance: post-welding inspection}

In any welding operation, there is always a chance of significant heat distortion. Because of this, the component positions might not be correct after welding has been completed, and so, these positions are re-measured immediately after welding. In the case of an out-of-tolerance position, the process stops and the part is scrapped.

The measurement of the distorted component taken after welding is then used to compensate the pre-welding position of the component when the next part is built, as shown in Fig. 7. This is calculated the same way as the level 1 guidance.

In the literature, this is often referred to as run-to-run control, where the reproducibility of the process is improved based on measurements of previous runs. This method has been widely studied and applied in other industrial applications $[35,36]$.
In modern welding processes, the location and integrity of the weld seam are critical quality concerns. Traditionally, this is controlled with post-process manual inspection. There are some automated laser-based vision systems for inspecting the weld seams, but none of them are widely used due to their lack of reliability in real-life complex welding operations.

Weld seam inspection is also critical in the automated MAWC welding process. Therefore, level 2 guidance includes an inspection to check the integrity of the weld seam. In the case of poor quality weld seams, the MAWC reruns the welding operation or stops the process.

The weld seam inspection functionality has been shown to work in practice in one of the development projects, as outlined in Sect. 5.3.

\subsection{Level 3 guidance: inter-OP compensation}

Level 1 and level 2 guidance will automatically compensate most of the variation during the welding process.

However, another possible source of variation comes from heat distortion during later processes. It is possible that a subsequent welding operation causes some level of distortion in

\section{Welding process}

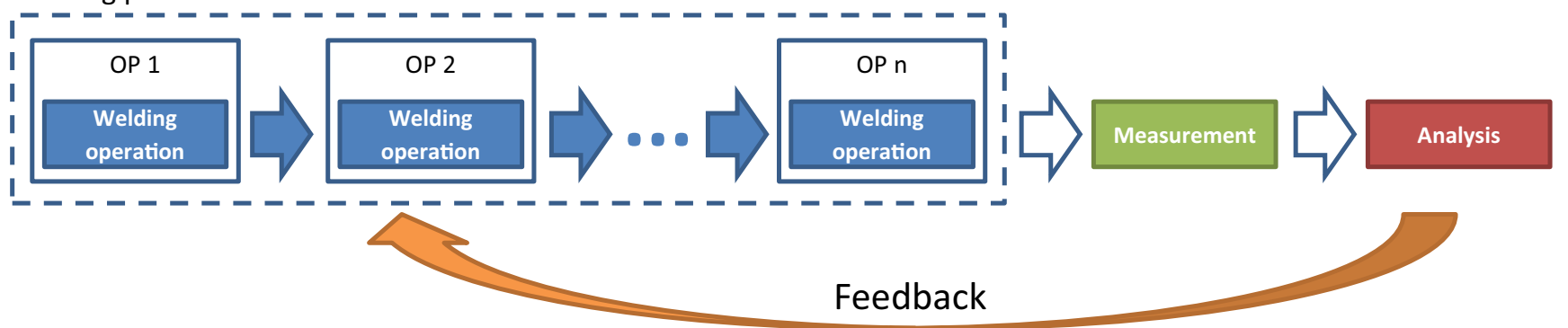

Fig. 5 Process adjustment of a traditional dedicated manufacturing line (DML) 


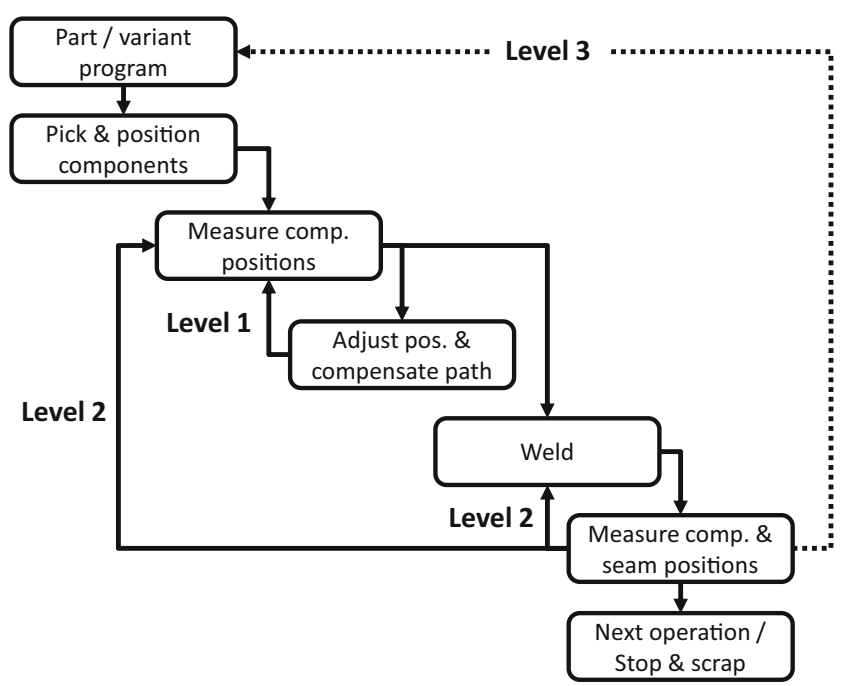

Fig. 6 The guidance actions during one MAWC operation step

the components which were originally welded correctly in previous operations.

This means that even though all previous operations have a sub-assembly within tolerance, the later operation may cause these areas of the part to distort out of tolerance. This is one of the reasons for long launch times in traditional welding fixtures (DWLs), which are measured only after the final operation. In the traditional process, it is virtually impossible to identify at which point of the process the distortion occurred, since only the eventual output can be measured.

Since the MAWC measures and records every operation, it is possible to analyse at which point of the process the distortion happens. The ability to compensate the positioning of components in earlier OPs is called level 3 guidance (as shown in Fig. 4).

This is not as straightforward as level 1 and level 2 guidance. Due to the complexity of the required analysis, this cannot be automated but requires human participation. This relates closely to the design principles of Industry 4.0, where the target is not to automate everything, but to enable communication between humans and machines through advanced analytics.

The use of these kinds of analytics in other industrial applications is well-documented in the literature. The method called "Stream of Variation for Multistage Manufacturing Processes" (SoV for MMP) is an analytical feedback process which is not meant to be automatic (at least in the near future).

SoV attempts to describe the production stream and data stream to analyse the variation across the MMP, which in this case are the multiple OPs. Each OP generates a dimensional variation in the sub-assembly, which accumulates while the sub-assembly moves through each of the OPs. The SoV of MMP approach tries to find ways to reduce the associated variations. This approach has been applied successfully in the automotive industry, in areas such as body-in-white assemblies [37].

There is commercial software available that is designed for understanding the streams of process variation. An example of such software is Mapvision Result Viewer, dedicated to automotive body and chassis welding processes. A screen shot of its Process Adjustment Tool is seen in Fig. 8 [38].

\section{Review of required technology}

The MAWC is a combination of many different kinds of technology. Everything required is already commonly used in the automotive industry in standard modern production equipment. It just needs to be put together to build a MAWC.

\subsection{Robots}

There are two types of robots used in the MAWC: handling robots and a welding robot. Measurement-based guidance removes the requirement for accurate positioning.

The reconfigurability of a MAWC requires versatile movements from both types of robots. The welder needs to be able
Part $\mathrm{n}$

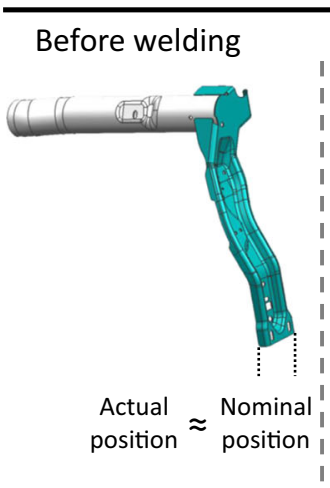

After welding

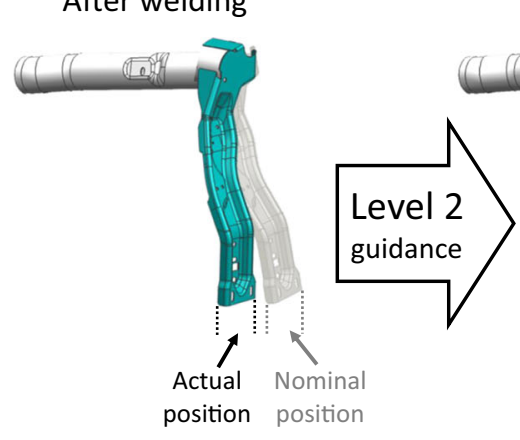

Before welding

Part $n+1$

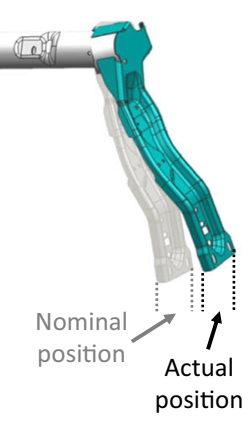

After welding

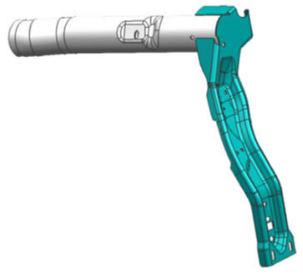

$\underset{\text { position }}{\text { Actual }} \approx \underset{\text { position }}{\text { Nominal }}$

Fig. 7 Level 2 guidance compensates the heat distortion 


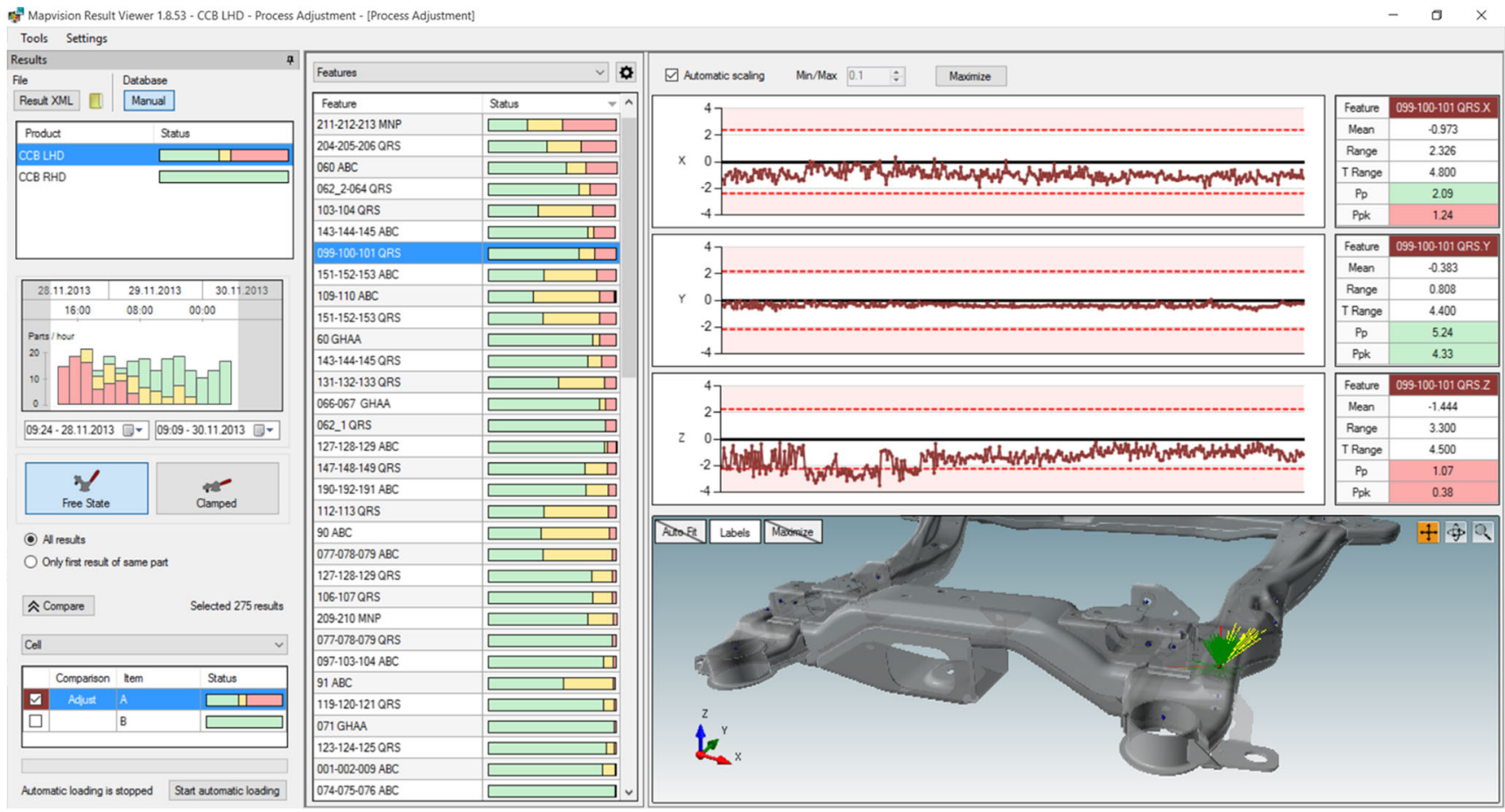

Fig. 8 Mapvision result viewer: process adjustment tool [38]

to access the part from any direction, and the components need to be positioned flexibly.

One example of the production robots available today is the Motoman range. The MH80 handling robot and MA1400 welding robot are both 6-axis robots, allowing the versatile movement needed for a MAWC. The "blind" positioning accuracy is less than $0.1 \mathrm{~mm}$ with both robots, which is well within range [39]. Pictures of the robots are seen in Fig. 9.

This demonstrates that the requirements for a MAWC can be satisfied with standard production equipment.

\subsection{Grippers}

There are two main requirements for the robot end-of-arm grippers used by the MAWC.

In order to be easy to reconfigure, the grippers need to be interchangeable. The robot can take one off and put another one on, just like a glove on a human hand. Interchangeable robot grippers have been used widely in the automotive industry for over 2 decades.

Reconfigurability is not really present if every component requires a dedicated gripper, no matter how quickly it could be changed. Therefore, the grippers need to be programmable and adjustable, depending on the components they hold. For example, the ROBOTIQ S-Model is capable of picking up completely different components. Its flexible finger-like appendages are seen in Fig. 10 [39].

From this, it is clear that the requirements for interchangeable and adaptive grippers can be met with standard production equipment.

\subsection{Robot guidance by measurement}

Adjusting or guiding the position of a robot based on measurements is not a new idea. There is a wide body of research looking into "camera-aided robot calibration". A visit to any robotic exhibition or automotive factory will show numerous applications and implementations.

The first automatically guided robot manufacturing systems based on multi-camera measuring were installed in an
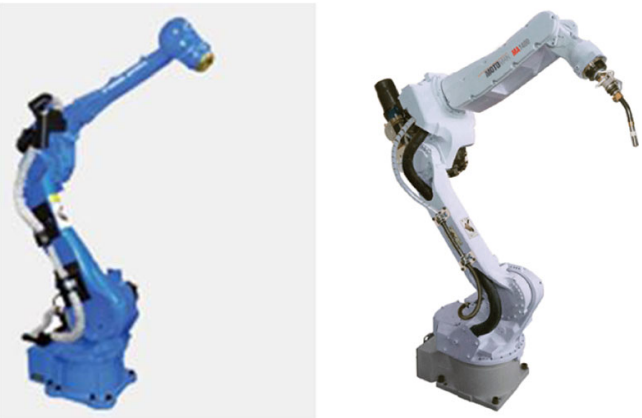

Fig. 9 Motoman MH80 handling robot (left) and Motoman MA1400 welding robot with a welding torch (right). Images: [39] 
Fig. 10 ROBOTIQ S-Model adaptive gripper holding different components [39]

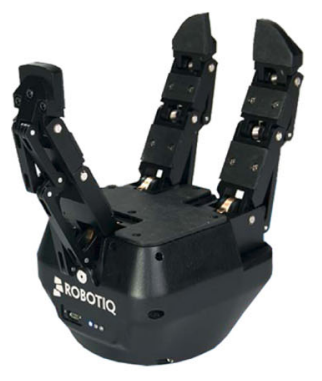

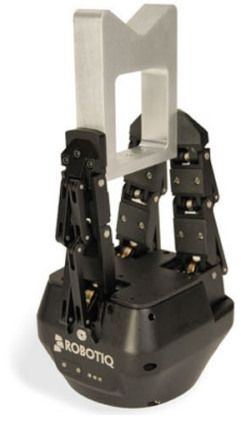

automotive manufacturing process at Valmet Automotive in Uusikaupunki, western Finland, in 1992. Four to eight cameras measured the position of a car body arriving at a robot seaming station. The exact position of the car body was input to the seaming robots, who translated it into their coordinate systems, so the robots could move along the correct seaming path even though there was no accurate mechanical positioning of the car body. This allowed the same seaming stations to be used for several different car models [40].

Therefore, it is clear that the requirements for robot guidance by measurement can be met with standard production equipment.

\subsection{Multiple robots as a workgroup}

Using multiple robots in cooperation in a group are becoming more and more common in different industries. The synchronized control of two robots became technically possible in 1994 when Motoman introduced the MRC. Four robots became possible in 2004 with the NX100. Currently, with the DX100, it is possible to synchronize eight robots together [39].

The academic literature sometimes describes robots used in a reconfigurable and changeable work group. The main idea of mobile manufacturing is to easily and quickly share manufacturing capacity between different projects. A manufacturing system in Västerås, Sweden, was an automatic assembly system consisting of two robots, gluing and folding stations and robot-handled tools, see Fig. 11 [41].

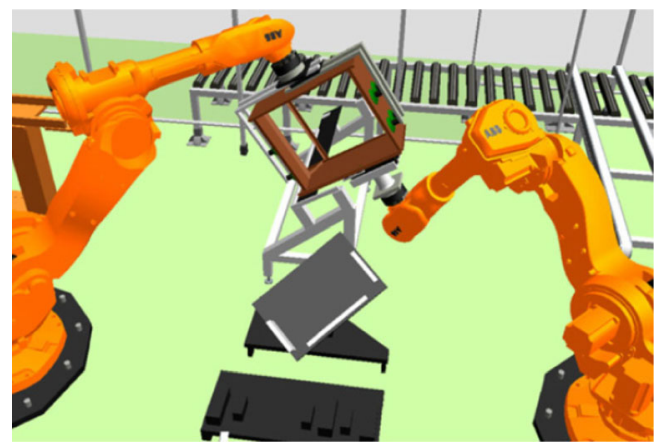

Fig. 11 "Factory-in-a-box" consisted of two robots in Västerås, Sweden. Image: [41]
From this, it is clear that the requirements for multiple robots working as a group can be met with standard production equipment.

\subsection{Real-time measurement}

Reconfigurable real-time measurement is the new technical element in a MAWC. The four critical characteristics of the measurement technology used in a MAWC are

- Speed

- Flexibility

- Global calibration volume

- Weld seam inspection

Speed Measurement technology needs to be fast enough to operate within the welding cycle. Although the available time for one measurement cycle is only a couple of seconds, in some cases, there might be dozens of measurement points that need to be measured.

Flexibility The measurement system needs to be able to measure hundreds of different points during the whole welding operation. There can be several different part variants and part families. Such complex measuring results in thousands of different measurement points that can be located anywhere in the measurement volume.

Global calibration volume Measurement results from different areas of the part need to be comparable across a global coordinate system in order to make automatic adjustments. This means that the measurement system needs to have one unified calibration volume. The global accuracy needs to be less than $\pm 0.1 \mathrm{~mm}$. Local accuracy is not sufficient.

Weld seam inspection In addition to the measurement task, the measurement technology needs to be able to inspect the quality of the weld seam after the welding operation.

Traditional measurement technology, such as laser sensor systems or robotized white light scanners, does not meet these requirements. This is why the development of a MAWC has 


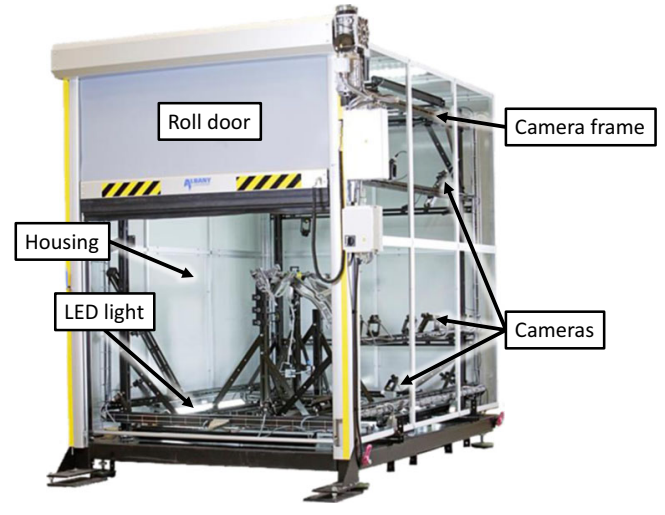

Fig. 12 Mapvision quality gate 4200 series. Image: [38]

not been possible before. Fixed laser sensor systems are fast enough but do not provide the flexibility nor the weld seam inspection capability. Robotized laser sensor systems or white light scanners are not fast enough nor would there be any room for additional robots in the cell. None of the traditional measurement technology has global calibration volume or is able to inspect weld seams [42-45].

At the time of writing, the only commercial product that can meet the requirements of a MAWC is Mapvision Quality Gate, an in-line measurement system already widely used across the automotive industry to check welded assemblies on the production line. It was introduced to the automotive industry in 2009. See Fig. 12.

The system uses a photogrammetric multi-camera technology, unlike any other commercial measurement system (Fig. 13). It can flexibly measure anything within the calibrated measurement volume. This is a key requirement for a MAWC.
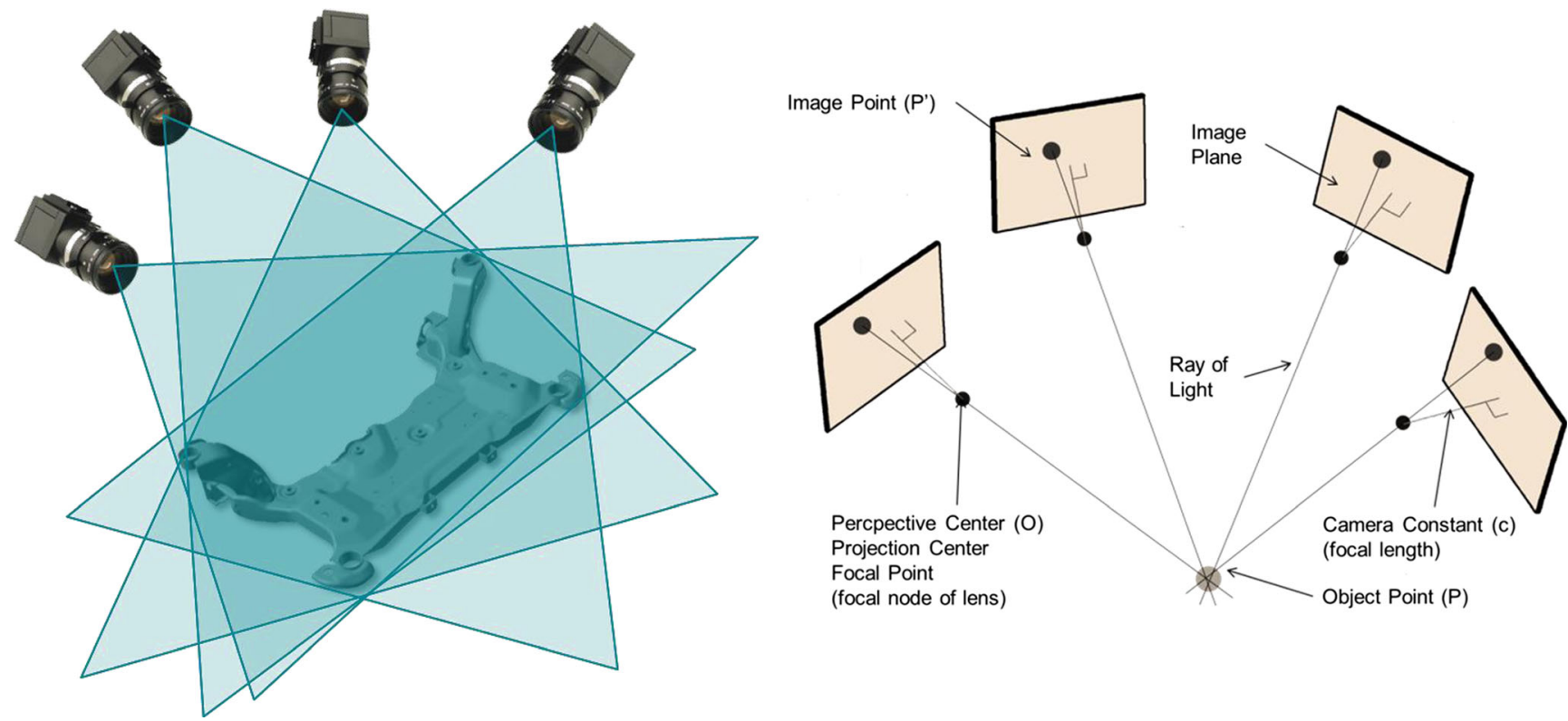

There have been three development and test projects to test and demonstrate the functionality of a MAWC.

The first and third of these projects were done in cooperation with BMW. The detailed technical information of these projects is confidential and therefore cannot be published. Without going into detail, this section explains the basic principles and final results of these projects. The second was done with VTT, the Finnish technology research institute. VTT is a government organisation, and the details of its research may be discussed freely.

The first BMW project and the VTT project focused on level 1 guidance. The third project (the second in BMW) examined the weld seam inspection function, which is level 2 . Level 2 guidance uses the same functionality as level 1 guidance for a different output.

Fig. 13 Basic principle of multi-camera measurement technology. Image: [38] 
All three projects were successful. Since Level 3 is a nonautomatic, human-based operation, all the required functionality of a MAWC was shown to work.

\subsection{Level 1—simple 2D welding robot guidance}

In 2011, BMW and Mapvision started a development project to explore the concept and functionality of the MAWC in practice. This project was carried out at BMW Dingolfing facilities in Germany.

The intention in this first project was to show the effectiveness of level 1 guidance with a simple test case. The test set-up used a 4200 Series Mapvision Quality Gate and a test platform with two movable plates. These plates represented components to be welded together. Only one of the plates was movable.

The test arrangement included four steps:

- Set the test plates to nominal starting position.

- Drive along the nominal welding path "blindly".

- Move the plate and measure its new position.

- Give adjustments to the welding robot and drive along the new adjusted welding path.

The test plate platform and the test welding process are shown in Fig. 14. This test assumed a simple 2D geometry, and the welding robot adjustments were done by giving the robot $2 \mathrm{D}$ offsets.

This test was successful. After moving the plate, the robot was able to drive along the new path accurately. This development was studied further under more comprehensive robot control (see Sect. 5.2)

\subsection{Level 1—robot guidance - 3D free-form robot guidance}

The second level 1 guidance development project increased the complexity of the task to free-form 3D guidance, in order to represent more realistic guidance.

Fig. 14 Turning the plate in the process of plate welding

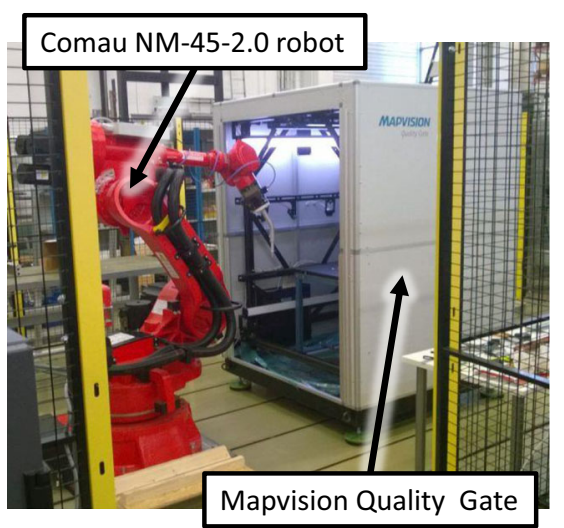

Fig. 15 Test set-up at VTT Tampere: Comau NM-45-2.0 robot and quality gate 2200 series

This project was run through the Finnish Metals and Engineering Competence Cluster (FIMECC) under "Future digital manufacturing technologies and systems" (MANU). The project name is "MAPweld", and the eventual goal is to build a pilot MAWC system.

During 2014 and 2015, development work was done in cooperation with VTT. In June 2015, a test was carried out at VTT Tampere in Finland. One Comau NM-45-2.0 robot was controlled by measurement data provided by a 2200 series Mapvision Quality Gate (as shown in Fig. 15).

The aim was to test the full functionality of robot guidance needed for level 1 in a MAWC (as shown in Fig. 6). This resulted in two test scenarios:

1. Positioning of the component for welding

2. Adjusting the welding path based on measurement

\subsubsection{Positioning of the component}

In a MAWC, the handling robot positions the component to be welded before welding.

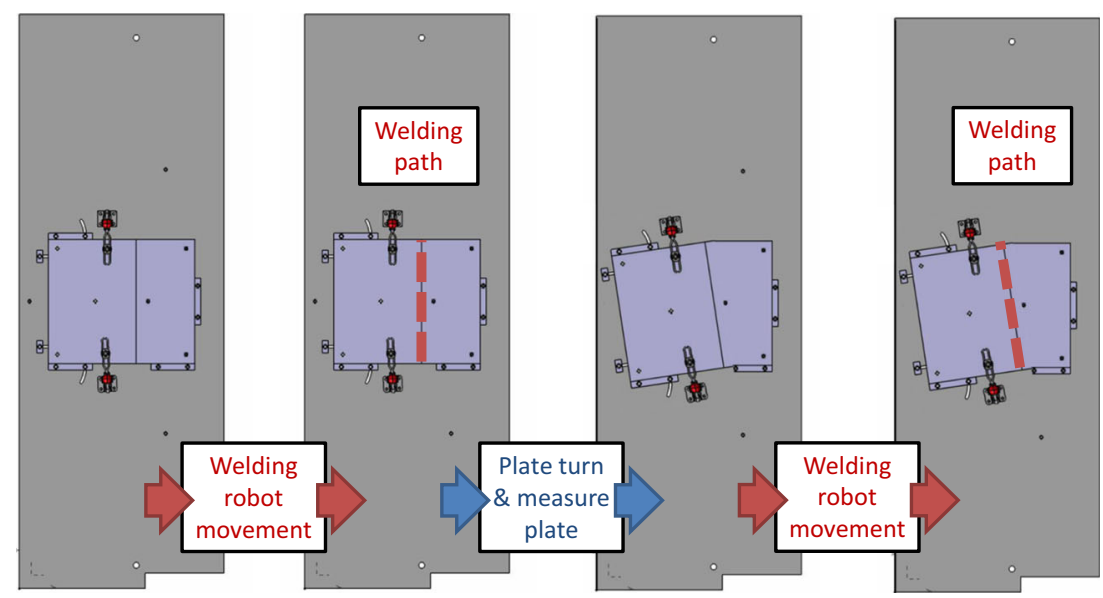


This was tested with three fixed white targets inside the Quality Gate unit. The targets defined the main coordinate system (as shown in Fig. 16) with a 3-2-1 alignment.

The test plate was the component to be welded. Three holes were programmed for measurement by Quality Gate (h0, h8 and h10 in Fig. 16). A sub-coordinate system was created from these three measured holes using a 3-2-1 alignment.

The sub-coordinate system was set to "zero" with the main coordinate system in the correct "welding position". The measured "tool-point" on the test plate was translated back to the main coordinate system, which gave the relation between the gripper and the test plate. By knowing this relation, it was possible to move the test plate to the correct "welding position" by giving the robot control software the resulting $4 \times 4$ transformation matrix.

This functionality was demonstrated by having the plate randomly $( \pm 10 \mathrm{~mm})$ positioned at the pickup station. The robot gripped the plate and put it into the Quality Gate unit. Quality Gate then measured the position of the plate. The difference was calculated and the robot adjusted the plate position based on the measurement. The correct position was verified by a second measurement in Quality Gate.

\subsubsection{Adjusting the welding path}

Before welding, a MAWC measures the position of the components to be welded together. In addition to adjusting the position of the components, done in the previous step, it also adjusts the welding path to ensure that the weld seam will also be in the correct position.

The targets were used as the reference for creating the main co-ordinate system (as in the previous test). The measured holes (h0, h3 and h5) created a sub-coordinate system (as seen in Fig. 17).

The test plate (the component to be welded) was placed inside the Quality Gate unit. The plate was moved randomly between each test round. Quality Gate measured the position of the plate and gave the transformation matrix to the robot. The welding robot had a black marker pen in its hand (to represent the welding gun). After correction, the robot drove

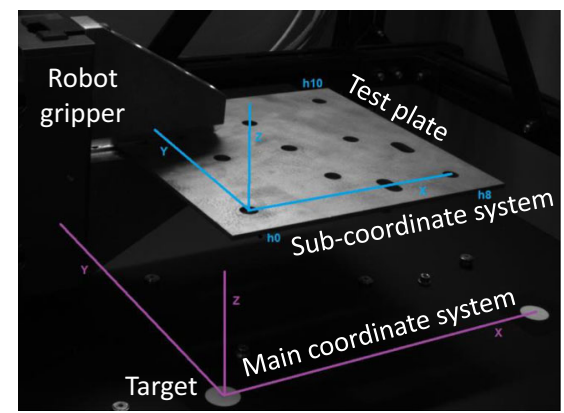

Fig. 16 Calculation of handling robot transformation matrix based on two coordinate systems

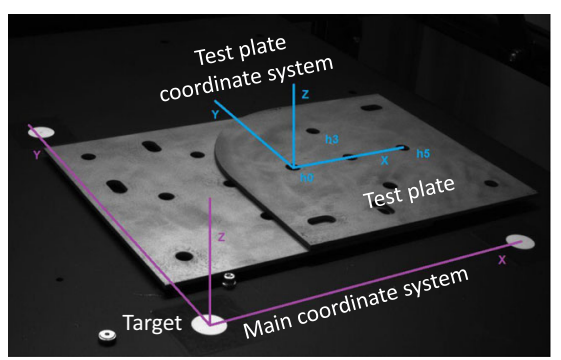

Fig. 17 Calculation of welding robot transformation matrix based on two coordinate systems

along the adjusted welding path.

The test was successful and the path was drawn accurately to the same place on the plate, whatever its location (Fig. 18).

In the first welding path adjustment test for BMW (section 5.1), there was a straight welding path and movement was in $2 \mathrm{D}$. In this test, the welding path was more complex (straight and round elements) and movements were in 3D.

\subsection{Level 2-weld seam inspection}

The third development project focused on evaluating the detection of errors in weld seams using the same multi-camera technology as in the measurement. This is a crucial functionality in level 2 guidance. Measurement technology needs to be able to verify each welding operation and, if necessary, initiate re-welding.

The measurement and positioning of components are done exactly the same way as in level 1 guidance. This functionality was already demonstrated clearly in the other two projects.

This third project was done in cooperation with BMW with the same 4200 Series Quality Gate system as in the first project. This time, the system was used to inspect the weld seams of a real production part. The chosen part was the aluminium front subframe from a Rolls-Royce Ghost (see Fig. 19).

The most important defects to be verified visually from a weld seam are

- Missing weld seam

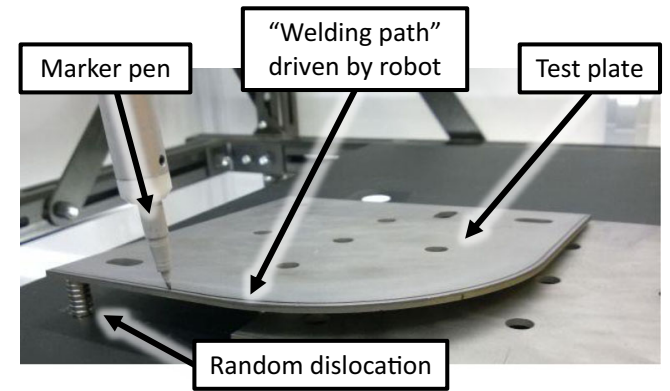

Fig. 18 Demonstrating the adjusted welding path with a black marker pen in the hand of the robot 


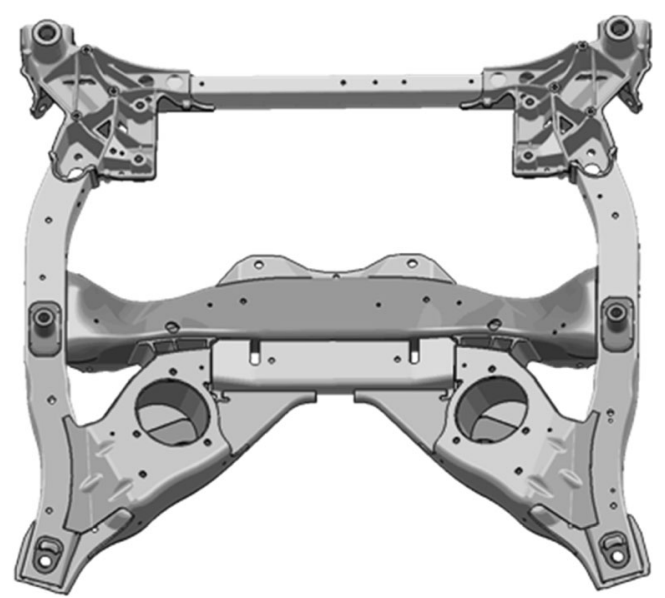

Fig. 19 Aluminium front subframe of a rolls-royce ghost

- Bad location of a weld seam

- Gap or a hole in the weld seam

- Bad quality weld seam

All of the defects were detected successfully in the test. Figure 20 shows some typical examples of each defect.

\section{Implications and benefits: comparison between MAWC and DWL}

This section looks at the main similarities and differences between a traditional dedicated welding line (DWL) and a measurement-aided welding cell (MAWC), using the process to manufacture an instrument panel support (IPS), as a case example.

\subsection{Flexibility for multiple products}

A traditional DWL produces only one product and can produce only a few similar variants of the same product. Any fundamental differences, such as the size or length of the basic elements, will introduce complexity and limitations. Producing different products in a DWL are practically impossible.

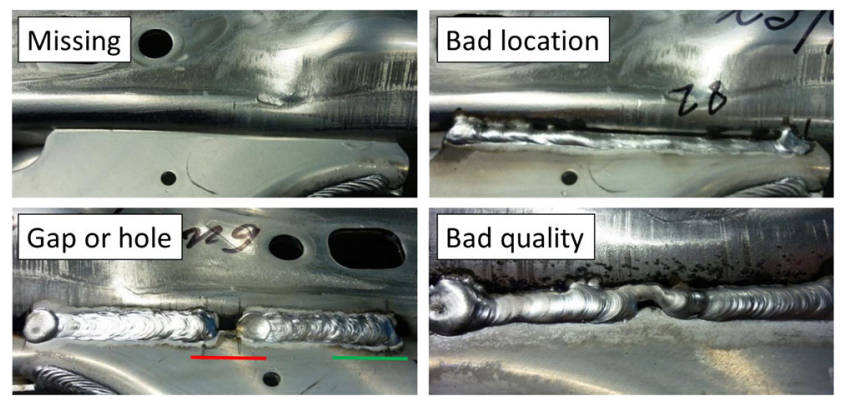

Fig. 20 Different weld seam defects detected successfully using mapvision quality gate
The heavily fixed mechanical structure of a traditional welding jig cannot be changed.

However, with a MAWC, there are no physical limitations on the number of different variants and products that can be produced. Even different product types (e.g., instrument panel supports and subframes) can be produced in one MAWC. Changing between different variants, products and product types is mainly a software task.

Figure 21 shows different variants, products and product types that can be produced with a DWL and MAWC.

Flexibility is what makes it possible to produce many different products in 1 day with a MAWC. The manufacture of low volume products is efficient, since capacity can be distributed to across multiple products. Previously, one DWL was needed for every low volume product, making small quantities expensive.

After the production of a car model has finished, the obligation to supply spare parts continues for several years. Currently, this means that the old production line (DWL) stands on a factory floor for years and is used only every now and then, when spare parts are needed. A MAWC would make it possible to produce different spare part types for several car models on demand using the same system. Spare parts could be a profitable business instead of just an obligation.

The same principle applies to low-volume luxury car manufacturing. A low DWL utilisation rate makes a return on the line investment take a long time and the price of a car high, which partly explains the tenfold price difference between an A-class and an SLS Mercedes-Benz. A MAWC would encourage a very high utilisation rate, since there would be multiple low-volume products produced in one system.

\subsection{Production capacity}

In traditional DWLs, several components are welded to the assembly during one operation (OP), which results in only a few separate OPs. They are designed for the OPs to be done in parallel to each other, so the total part-to-part cycle time is close to the individual OP cycle time. A typical high-volume DWL cycle time for an instrument panel support is $1 \mathrm{~min}$.

In contrast, a MAWC can weld only one component at a time to the assembly. This means that a significantly larger number of OPs is needed.

The sample case IPS has 16 components to be welded. This requires three welding operations in the DWL and 15 welding operations in the MAWC, as is shown in Fig. 3. Since the runtime of one operation in the MAWC is $15 \mathrm{~s}$, the total part-to-part cycle time in this case example is 3 min and 45 s (Sect. 3.1 details cycle times). Highvolume DWLs are capable of running with less than 1 min part-to-part cycle time. 
Fig. 21 Variants, products and product types (IPS and subframe)
DWL MAWC

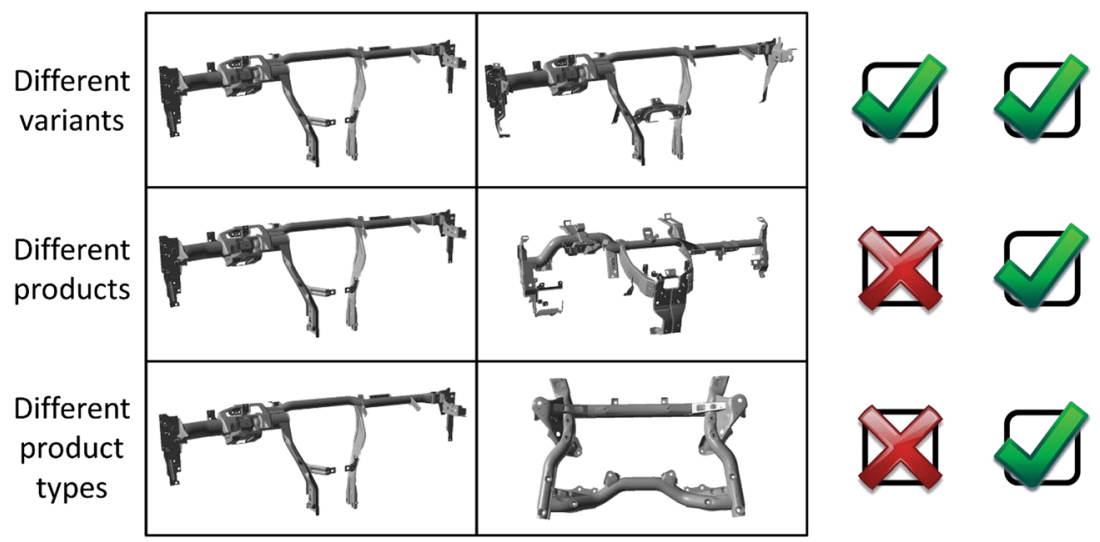

The maximum capacity of one DWL can be up to 500,000 parts per year. With its longer cycle time, one MAWC can reach a maximum capacity of about 100,000 parts per year.

High-volume products have production volumes typically between 100,000 and 500,000 parts per year. This means that in some cases, there should be several MAWCs replacing one DWL to reach peak volume.

\subsection{Life cycle investment costs}

The design of a DWL starts a long time before the production line is built. Investment in the purchase of all the necessary customized equipment must also be done before the first parts can be produced. Even so, a DWL is almost always designed for maximum capacity. This is called the "reserved capacity".

After the DWL is ready to produce its first parts, there is a long launch period, throughout which it is adjusted. After the start of production (SOP), production capacity is slowly increased. Usually, a DWL is run at full capacity for only a couple of years, after which production volumes fall, and finally, the equipment is dismantled. This life cycle is typically 8 years but has been recently shortening as product cycles shrink.
The life cycle of a MAWC is completely different. Design can start later, since it is a standard cell, and all the partspecific design is done in a virtual CAD environment. The first prototype parts and low volumes in the first years can be produced with only one MAWC. Additional MAWCs can be introduced based on actual demand by assigning more standard cells and copying the software-based production parameters from the first cell.

When using DWLs, the investment cost is dependent on expectations at the beginning of the life cycle, whereas the cost of a MAWC is dependent on actual demand. This difference can be seen in graphs in Fig. 22.

The true benefit of a MAWC is realised when a number of different products are being manufactured in the same factory at the same time. Most of the products are not produced at maximum capacity. Since one MAWC can deal with several products at the same time, MAWC capacity can be averaged, outputting many low-volume products in one system. This maximises the utilisation of MAWC capacity.

With a DWL, most of the lines would be running below maximum capacity. Yet, all of the equipment is being used and all of the floor space is occupied.

\section{DWL Lifecycle}

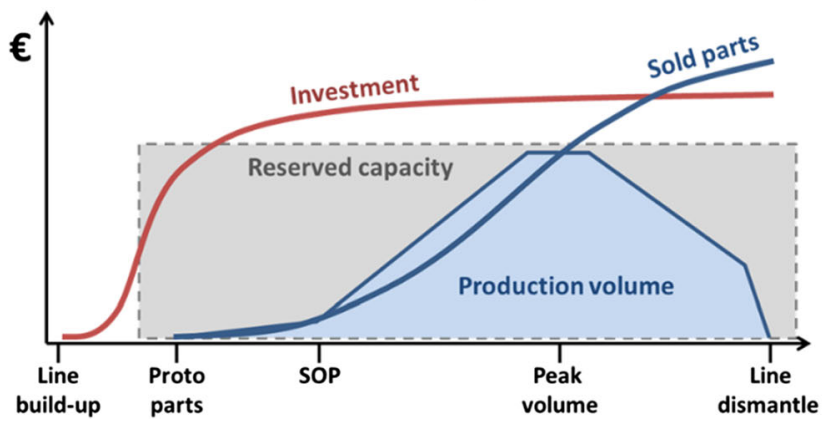

MAWC Lifecycle

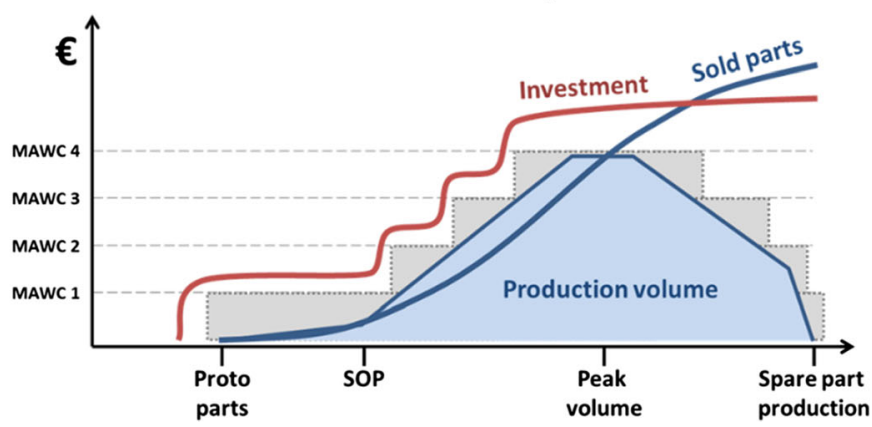

Fig. 22 Production lifecycle with investment cost. Comparison of a DWL and MAWC 


\section{Summary and conclusions}

Global megatrends in the automotive industry are creating pressures for manufacturing systems to become more flexible. Many automotive manufacturing processes have moved in this direction, such as machining and laser cutting. However, there are no easily adaptable manufacturing systems available for welding.

Currently, automatic welding is the most common way to manufacture structural car parts. The usual method, using a blind dedicated welding line (DWL) with heavyweight mechanical fixtures, is inflexible. The heavy mechanical structure makes it technically impossible and uneconomical to modify the blind DWL.

The concept of a measurement-aided welding cell (MAWC) answers this challenge. The MAWC is based on the principle that the welding operation is controlled by a measuring system giving guidance and intelligent feedback to the welding robots on three different levels: before and after welding as well as analysis across the whole process.

A MAWC allows the user to change almost instantly between manufactured products, increasing the utilisation rate and making it possible to adjust capacity according to demand. This flexibility increases the production capacity of a factory while significantly reducing the investment costs into manufacturing lines. A MAWC also offers the chance to produce several different low-volume products in one manufacturing system. This has the potential to open completely new markets and business opportunities in the automotive industry.

When using MAWCs, investing in manufacturing capacity starts much later in the product life cycle. This makes it possible to answer fluctuating demand without early and heavy financial outlay. This is a key element to maintaining cost efficiency, even though the life cycle of cars is getting shorter and shorter.

The concept of measurement-assisted assembly and machining is not new. However, this concept has not been applied to complex welding processes before due to the technical requirements of the measurement technology. None of the traditional measuring techniques have met the requirements of speed, flexibility, global calibration volume and the ability to inspect weld seams.

In 2009, such a measurement technology was introduced into the market. Every other necessary technology is available and already widely used in the industry. The main functionality has already been developed and demonstrated. The development of the MAWC has the support of major automotive companies, including BMW.

It seems that measurement-aided welding is possible and that we will be able to redefine the very core of car manufacturing. It is almost as if we are able to give sight to the blind!

Open Access This article is distributed under the terms of the Creative Commons Attribution 4.0 International License (http:// creativecommons.org/licenses/by/4.0/), which permits unrestricted use, distribution, and reproduction in any medium, provided you give appropriate credit to the original author(s) and the source, provide a link to the Creative Commons license, and indicate if changes were made.

\section{References}

1. Berger R (2012) Mastering product complexity. Roland Berger Strategy Consultants

2. Pine BJ (1993) Mass customization: the new frontier in business competition. Harvard Business School Press, Boston

3. Shimokawa K, Jürgens U, Fujimoto T (eds) (1995) Transforming automobile assembly: experience in automation and work organization. Springer, Berlin

4. Cusumano MA (1985) The Japanese automobile industry. TECHNOLOGY and management at Nissan and Toyota. Council on East Asian Studies, Harvard University, Cambridge

5. Fujimoto T (1999) The evolution of a manufacturing system at Toyota. Oxford University Press, New York

6. Liker J (2003) The Toyota way: 14 management principles from the world's greatest manufacturer. McGraw-Hill, New York

7. Monden Y (1983) Toyota production system: practical approach to production management. Industrial Engineering and Management Press, Norcross, GA

8. Womack JP, Jones DT, Roos D (1990) The machine that changed the world: the story of lean production. Perennia, New York

9. Clark KB, Fujimoto T (1991) Product development performance. Harvard Business School Press, Boston

10. Cusumano M, Nobeoka K (1998) Thinking beyond lean: how multiproject management is transforming product development at Toyota and other companies. Free Press, New York

11. ElMaraghy HA (2006) Flexible and reconfigurable manufacturing systems paradigms. Int J Flex Manuf Syst 2006(17):261-276. doi: 10.1007/s10696-006-9028-7

12. Wiendahl $\mathrm{H}$ (2005) Justifying changeability. a methodical approach to achieving cost effectiveness. Int J Manufac Sci Prod 6(1-2):33

13. Nyhuis P, Kolakowski M, Heger CL (2006) Evaluation of factory transformability - a systematic approach. Prod Eng 13(1):147-152

14. Dove R (1994) The meaning of life and the meaning of agile. Production 106(11):14-15

15. Goldman SL, Nagel RN, Preiss K (1995) Agile competitors and virtual organizations. Van Nostrand Reinhold, New York

16. Yusuf YY, Sarhadi M, Gunasekaran A (1999) Agile manufacturing: the drivers, concepts and attributes. Int J Prod Econ 62(1-2):33-43

17. Gunasekaran A, Yusuf YY (2002) Agile manufacturing: a taxonomy of strategic and technological imperatives. Int J Prod Res 40(6): $1357-1385$

18. Slack N (1988) Manufacturing system flexibility—an assessment procedure. Comput-Integrat Manufac Syst 1(1):25-31

19. Upton DM (1994) The management of manufacturing flexibility. Calif Manag Rev 36(2):72-89

20. Upton DM (1995) Flexibility as process mobility: the management of plant capabilities for quick response manufacturing. J Oper Manag 12(3-4):205-224

21. Park TH, Lee HC, Lee HS (2001) FMS design model with multiple objective using compromise programming. Int J Prod Res 39(15): 351328 
22. Koren Y, Heisel U, Jovane F, Moriwaki T, Pritschow G, Ulsoy G, Van Brussel H (1999) Reconfigurable manufacturing systems. CIRP Ann Manuf Technol 48(2):527-540

23. Fujii S, Morita H, Kakino Y, Ihara Y, Takata Y, Murakami D, Miki T, Tatsuta Y (2000) Highly productive and reconfigurable manufacturing system. Proc Pacific Conf Manufac 2:970-980

24. Koren Y, Shpitalni M (2010) Design of reconfigurable manufacturing systems. J Manuf Syst 2010(29):130-141

25. Jackson M (2000) An analysis of flexible and reconfigurable production systems. Doctoral thesis. Sweden: Department of Mechanical Engineering, Linköping Universitet

26. Mehrabi MG, Ulsoy AG, Koren Y (2000) Reconfigurable manufacturing systems: key to future manufacturing. J Intell Manuf 11:403-419

27. Wemmerlov U, Hyer N (1989) Cellular manufacturing in the US industry: a survey of users. Int J Prod Res 27(9):1511-1530

28. Wemmerlov U, Johnson DJ (1997) Cellular manufacturing at 46 user plants: implementation experiences and performance improvements. Int J Prod Res 35(1):2949

29. Wemmerlov U, Johnson DJ (2000) Empirical findings on manufacturing cell design. Int J Prod Res 38(3):481507

30. Won Y, Currie KR (2006) An effective p-median model considering production factors in machine cell/part family formation. J Manuf Syst 25(1):5864

31. Balakrishnan J, Cheng CH (2007) Multi-period planning and uncertainty issues in cellular manufacturing: a review and future directions. Eur J Oper Res 177(1):281309

32. Javadian N, Aghajani A, Rezaeian J, Sebdani MJG (2011) A multiobjective integrated cellular manufacturing systems design with dynamic system reconfiguration. Int J Adv Manuf Technol 56: 307-317. doi:10.1007/s00170-011-3164-2

33. Renna P, Ambrico M (2015) Design and reconfiguration models for dynamic cellular manufacturing to handle market changes. Int $\mathbf{J}$ Comput Integr Manuf 28(2):170-186. doi:10.1080/0951192X. 2013.874590
34. Ah Kioon S, Bulgak AA, Bektas T (2009) Integrated cellular manufacturing systems design with production planning and dynamic system reconfiguration. Eur J Oper Res 192(2009):414-428

35. Del Castillo E (2002) Statistical process adjustment for quality control. Wiley, New York

36. Del Castillo E (2006) Statistical process adjustment: a brief retrospective, current status, and some opportunities for further work. Statistica Neerlandica 60(3):309-326

37. Shi J (2006) Stream of variation modeling and analysis for multistage manufacturing processes. CRC Press. ISBN 0-8493-2151-4

38. Mapvision web site and marketing material. www.mapvision.fi

39. Motoman Yaskawa web site (2012) Visited 20.10.2012. http:// www.motoman.eu/products/robots/

40. Haggren H (1993) Vision system for 3D car-body orientation, Proc. SPIE 1820, Videometrics, 132. doi:10.1117/12.141375

41. Stillström C, Jackson M (2007) The concept of mobile manufacturing. J Manuf Syst 26:188-193

42. Perceptron web site and marketing material. www.perceptron.com

43. Isravision web site and marketing material. www.isravision.com

44. Cognitens web site and marketing material. www.cognitens.com

45. Hexagon web site and marketing material. www.hexagon.com

46. Tuominen V (2011) Virtual clamping in automotive production line measurement. Expert Syst Applic 38(2011):15065-15074

47. Tuominen V, Niini I (2008) Verification of the accuracy of a realtime optical 3D-measuring system on production line. Int Arch Photogrammetr, Rem Sens Spatial Inform Sci 38, Part B5-1, Comission V 13-19. ISSN 1682-1750

48. MSA (2002) Measurement system analysis, reference manual, Third Edition. Automotive Industry Action Group. ISBN 978-160-534082-1

49. Tekes report - the Finnish Funding Agency for Technology and Innovation. http://www.tekes.fi/fi/community/Asiakkaiden tuloksia/403/Asiakkaiden_tuloksia/647?name=Optinen+ laadunvalvonta + autotehtaiden+tuotantolinjoille 